\title{
PROJETO DE PASSARELA PARA LIGAÇÃO ENTRE O PRÉDIO DOS LABORATÓRIOS DE ARQUITETURA E O PRÉDIO DO PPGAU NO CENTRO DE TECNOLOGIA DA UFRN
}

\section{PROYECTO DE PASARELA PARA VINCULAR EL EDIFICIO DE LABORATORIOS DE ARQUITECTURA Y EL EDIFICIO PPGAU EN EL CENTRO DE TECNOLOGÍA UFRN}

\section{WALKWAY PROJECT TO LINK THE ARCHITECTURE LABORATORIES BUILDING AND THE PPGAU BUILDING AT THE UFRN TECHNOLOGY CENTER}

\section{LIMA, MÔNICA MARIA FERNANDES DE}

Professora Doutora do DARQ/UFRN, e-mail: monicamfl@gmail.com

\section{LIMA, SABRINNY RAKEL SILVA DE}

Mestranda em Arquitetura e Urbanismo pelo PPAPMA/UFRN, e-mail: sabrinnylima@gmail.com

\section{SOUZA, IRAN LUIZ SEABRA}

Mestrando em Arquitetura e Urbanismo pelo PPGAU/UFRN, e-mail: iran.arq@gmail.com

\section{SERRANO, MARCELA LEMOS GOMES AGUIAR \\ Mestranda em Arquitetura e Urbanismo pelo PPAPMA/UFRN, e-mail: marcela.Igaguiar@gmail.com}

\section{RESUMO}

Este artigo apresenta o resultado produzido pelo grupo 03 na disciplina ofertada no período 2019.1 do Mestrado Profissional em Arquitetura e Urbanismo da Universidade Federal do Rio Grande do Norte (UFRN) - Oficina de Projeto Computacional - cujo enfoque foi a aprendizagem do desenho paramétrico através dos softwares Rhinoceros e Grasshopper aplicada ao projeto arquitetônico, tendo como produto final a proposta de projeto para uma passarela interligando o prédio dos laboratórios do curso de Graduação em Arquitetura e Urbanismo e o novo prédio em execução do Programa de Pós-Graduação em Arquitetura e Urbanismo (PPGAU). Dando início ao processo, o grupo fez análises de referências de projetos correlatos, sequido da definição do conceito. Após esta etapa, foram realizados estudos diversos e elaboração da proposta em desenho paramétrico. Por fim, o grupo obteve o modelo 3D virtual parametrizado, o qual foi apresentado aos professores participantes da banca de avaliação para análise e seleção da proposta vencedora, a ser executada em maquete física.

PALAVRAS-CHAVE: projeto de arquitetura; projeto paramétrico; passarela;

\section{RESUMEN}

Este artículo presenta los resultados producidos por el grupo 03 en el curso ofrecido en 2019.1 del Master Profesional en Arquitectura y Urbanismo de la Universidad Federal de Río Grande del Norte (UFRN) - Taller de Diseño Computacional - que se centró en el aprendizaje del diseño paramétrico a través del software. Rhinoceros y Grasshopper aplicaron al proyecto arquitectónico, teniendo como producto final la propuesta de proyecto para una pasarela que conecta el edificio de la licenciatura en Arquitectura y Urbanismo y el nuevo edificio en ejecución del Programa de Posgrado en Arquitectura y Urbanismo (PPGAU) ) Al comenzar el proceso, el grupo realizó análisis de referencia de proyectos relacionados, seguido de la definición del concepto. Después de esta etapa, se realizaron varios estudios y la elaboración de la propuesta en diseño paramétrico. Finalmente, el grupo obtuvo el modelo virtual 3D parametrizado, que se presentó a los maestros que participaron en el panel de evaluación para el análisis y la selección de la propuesta ganadora, que se realizará en un modelo físico.

PALABRAS CLAVE: proyecto de arquitectura; proyecto paramétrico; pasarela

\section{ABSTRACT}

This article presents the results produced by group 03 in the course offered in 2019.1 of the Professional Master in Architecture and Urbanism of the Federal University of Rio Grande do Norte (UFRN) - Computational Design Workshop - which focused on learning parametric design through software. Rhinoceros and Grasshopper applied to the architectural project, having as its final product the project proposal for a catwalk connecting the building of the undergraduate degree in Architecture and Urbanism and the new building in execution of the Graduate Program in Architecture and Urbanism (PPGAU)). Starting the process, the group made reference analyzes of related projects, followed by the definition of the concept. After this stage, several studies were performed and the proposal elaboration in parametric design. Finally, the group obtained the parameterized virtual 3D model, which was presented to the teachers participating in the evaluation board for analysis and selection of the winning proposal, to be performed on a physical model.

KEYWORDS: architectural design; parametric design; walkway. 


\section{INTRODUÇÃO}

Este trabalho foi elaborado para conclusão da disciplina de Oficina de Projeto Computacional, ministrada no Programa de Pós-graduação em Arquitetura e Urbanismo da UFRN (PPGAU).

O objetivo do exercício foi apresentar proposta para uma cobertura, de forma complexa, criada com o auxílio dos softwares Grasshopper e Rhinoceros, com o intuito de realizar a conexão entre o prédio dos Laboratórios de Arquitetura e o prédio do PPGAU, ambos situados no Centro de Tecnologia da UFRN. Como restrições, foram apresentadas:

- Edifícios existentes a conectar (implantação, forma, estética, materiais e sistemas construtivos dos dois prédios);

- Previsão de expansão do edifício novo;

- Topografia existente;

- $\quad$ Sistema de drenagem / grelhas;

- Agenciamento do piso;

- Árvore existente - Angico (a preservar);

- Paisagismo proposto - espécies para recobrimento da estrutura;

Com as informações acima, o grupo iniciou o estudo para o desenvolvimento da proposta, conforme será apresentado no decorrer deste artigo.

\section{REFERÊNCIAS PROJETUAIS E CONCEITOS}

A pesquisa se iniciou a partir do estudo de referências projetuais. $O$ grupo fez diversas pesquisas, principalmente de aspectos formais, e por fim selecionou dois projetos para uma análise mais aprofundada. Estes foram escolhidos considerando: localização do projeto, decisões projetuais, técnica construtiva, materiais, forma e conceito.

\section{Referência 01 - Estrutura em madeira em Valparaíso}

O primeiro projeto que utilizamos como referência foi o de uma estrutura de madeira executada em Valparaíso, Chile, em 2016.

A estrutura foi desenvolvida por estudantes do primeiro ano da Universidade Técnica Federico Santa Maria, juntamente com a arquiteta convidada Verónica Arcos. Esse trabalho teve duração de três semanas, sendo continuação de outro do ano anterior em que se estudou a obra do arquiteto Félix Candela.

A ideia do exercício era de construir uma estrutura estável de curvatura dupla, que deveria ser desenvolvido utilizando 8 módulos, cuja função seria criar uma passagem sombreada no local em que se forma a fila para o refeitório da universidade ${ }^{1}$.

Primeiro, as equipes desenvolveram propostas de projeto e em seguida foi feito um concurso interno de projeto na qual a opção foi escolhida, sendo feito o protótipo e logo após sua execução em tamanho real. A opção vencedora foi executada por todas as equipes, sendo cada uma responsável por um módulo²

A escolha por esse projeto como uma das referências se deu tanto pelo aspecto formal, quanto em razão da semelhança temática, pois foi uma proposta desenvolvida em circunstâncias semelhantes a do projeto em questão e com uso de peças simples de madeira, mesmo material que o grupo pensou em utilizar no projeto.

\section{Referência 02 - Passarela da linha verde UFPR}

O segundo projeto analisado foi o da passarela da Linha Verde na UFPR - Curitiba/PR, do ano 2000, desenvolvido pelo arquiteto Fernando Canalli.

Diferentemente do primeiro estudo, este possui como material o aço, mas por ser um elemento esbelto e de forma simples, em que se percebe a possibilidade de parametrização, estar em uma realidade semelhante por ser localizado também em uma universidade pública brasileira, o grupo considerou como interessante para esse estudo inicial ${ }^{3}$. 
O arquiteto utilizou tubos de aço na estrutura do elemento, que se entrelaçam formando um desenho lúdico para quem está passando por dentro do percurso. De acordo com a pesquisa, o conceito utilizado foi de uma flor de Lótus, e segundo o arquiteto, a ideia era se ter uma perspectiva que fosse evoluindo enquanto se transitava pela passarela. As pétalas se desenvolvem conforme se vai caminhando. Os desenhos da flor de lótus têm uma evolução muito similar, tendo sido a principal inspiração para o projeto. $\mathrm{O}$ arquiteto quis propor um desenho contemporâneo, dinâmico e agradável aos pedestres ${ }^{4}$.

Seguindo a ideia de leveza da estrutura, o piso da ponte é vazado, permitindo que os pedestres possam ver os carros passando pela rodovia.

\section{Conceito}

Para o conceito do projeto, nos utilizamos de uma das diretrizes fundamentais para o desenvolvimento da proposta, a árvore que deveria ser mantida, sendo o ponto de partida para definição do conceito então, os galhos e suas ramificações

Pensando na viabilidade de execução do projeto, o grupo racionalizou o conceito para uma estrutura mais regular e otimizada, surgindo o conceito de ramos em "leque", como uma palmeira Ravenala.

A ideia de leque evoluiu para uma outra ideia, de se fazer as estruturas de forma tal que causassem a sensação de um caminho demarcado por palmeiras, conferindo imponência e beleza à passagem que liga os prédios.

\section{PROCESSO DE DESENVOLVIMENTO DA PROPOSTA}

\section{Diretrizes gerais}

O elemento arquitetônico a ser criado é de uma estrutura para proteção contra sol e chuva no caminho que interliga os prédios do Departamento de Arquitetura da UFRN (Figura 1 e Figura 2). Antes das primeiras proposições, o grupo considerou como um dos pontos principais, o desenvolvimento de uma estrutura que possibilitasse o uso de telhas.

Uma outra preocupação do grupo foi criar um elemento que utilizasse apenas os itens disponíveis na lista de materiais do sistema da UFRN, fornecida pelos professores, além de ser de fácil execução e baixo custo, uma vez que trata-se de uma universidade pública, que vem sofrendo com retenções de gastos. Assim, optamos pelo uso de caibros e linhas, elementos esses que seriam conectados através do uso de parafusos e chapas metálicas. Por terem seção maior do que ripas, conferem maior resistência à estrutura.

Figura 1 - Visualização em 3D do local de implantação do elemento de cobertura

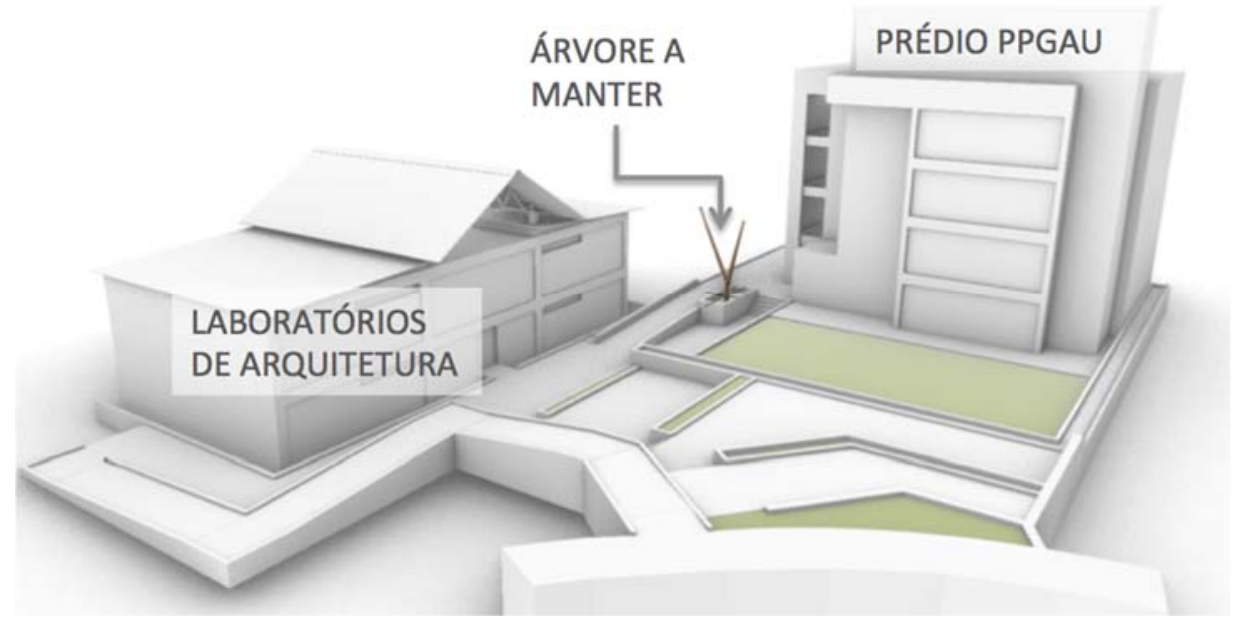

Fonte: Arquivo anexo ao Sigaa pelos discentes da disciplina, alterado pelos autores, 2019 
Figura 2 - Planta geral de implantação da área com indicação do local de inserção do elemento projetado

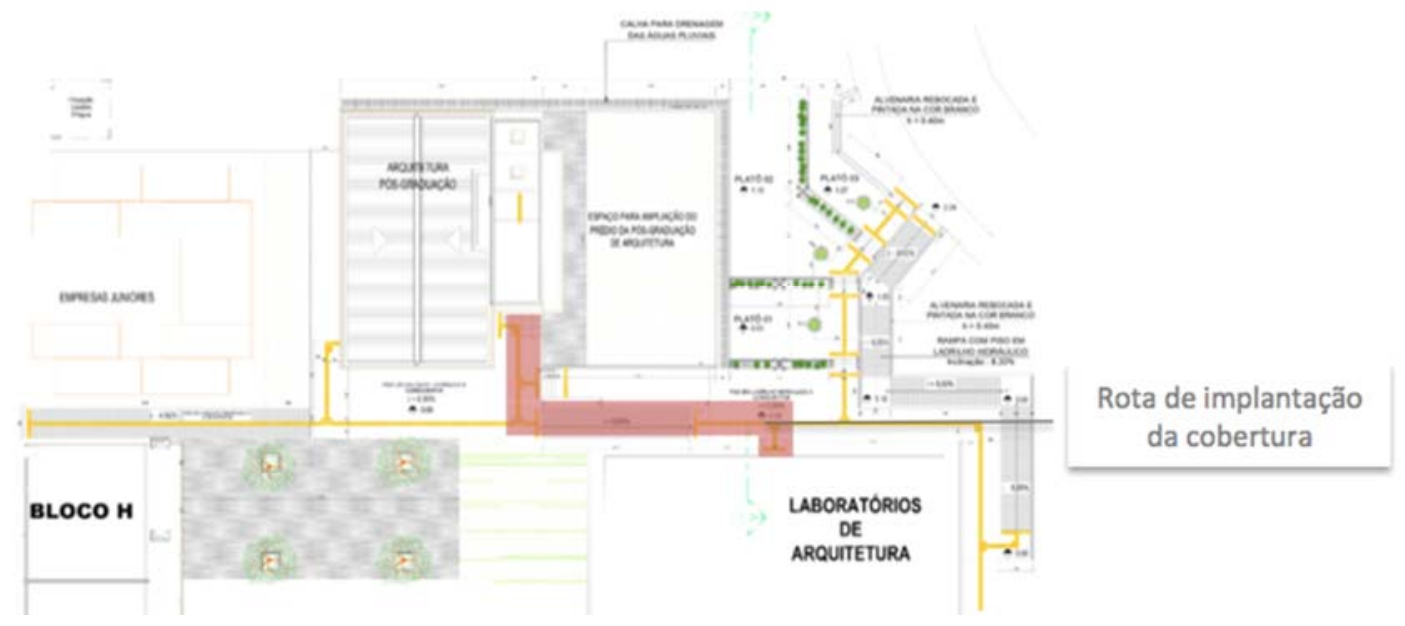

Fonte: Arquivo anexo ao Sigaa pelos discentes da disciplina, alterado pelos autores, 2019.

Após os estudos de referência, definição do conceito a ser adotado e diretrizes gerais a seguir, foi proposto um concurso de ideias interno ao grupo, no qual cada integrante deveria conceber um estudo inicial para que se elegesse uma das opções e, a partir dessa, o processo de projetação seria desenvolvido.

\section{Primeiras ideias}

O estudo escolhido foi desenvolvido no software Sketchup (Figura 3 - a), e consiste na criação de um pilar com ripas agrupadas em formato de leque que se repete ao longo de todo o percurso e a partir deste, o grupo foi testando variações da ideia e de como seria feita a cobertura, tanto em relação ao desenho, quanto em relação à questão de inclinação e execução (Figura 3 - b,c).

Figura 2 - Opção escolhida e estudos iniciais de evolução dessa proposta
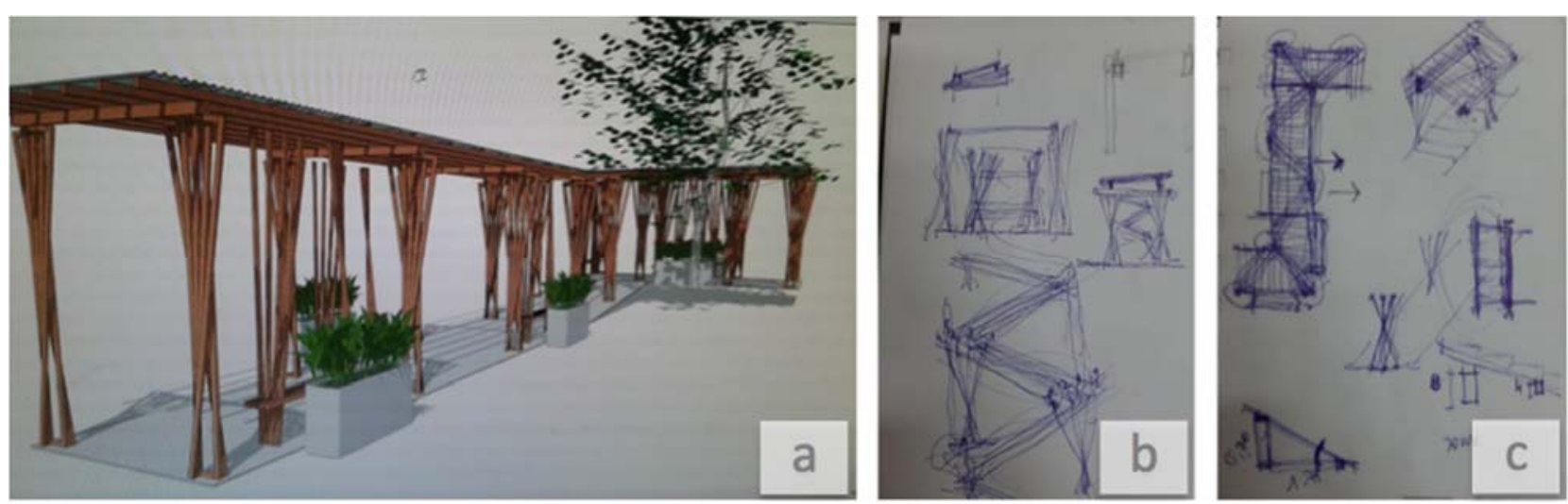

Fonte: Material produzido pelos autores, 2019. 
Nos primeiros croquis da cobertura, partindo dessa ideia inicial, o grupo pensou em intercalar os pilares e os interligar na diagonal, criando um movimento na coberta. Entretanto, esbarramos na questão da telha com essa solução, o que ocasionou a continuação dos estudos.

\section{Evolução da proposta}

Seguiu-se o desenvolvimento de estudos em croquis para a cobertura (Figura 3 - a) e as possibilidades de formato da estrutura, sendo pensada uma solução com peças verticais apenas de um lado (Figura 3 - b), mas que foi descartada por ter sido deduzido que a sustentação seria mais complicada nessa situação.

Também foi reavaliado o formato do leque em relação à estabilidade e fixação das peças, sendo pensado um leque em formato de "V", que se conectam nas extremidades, tendo uma continuidade no desenho (Figura 3 - C).

Figura 3 - Croquis de evolução da proposta inicial
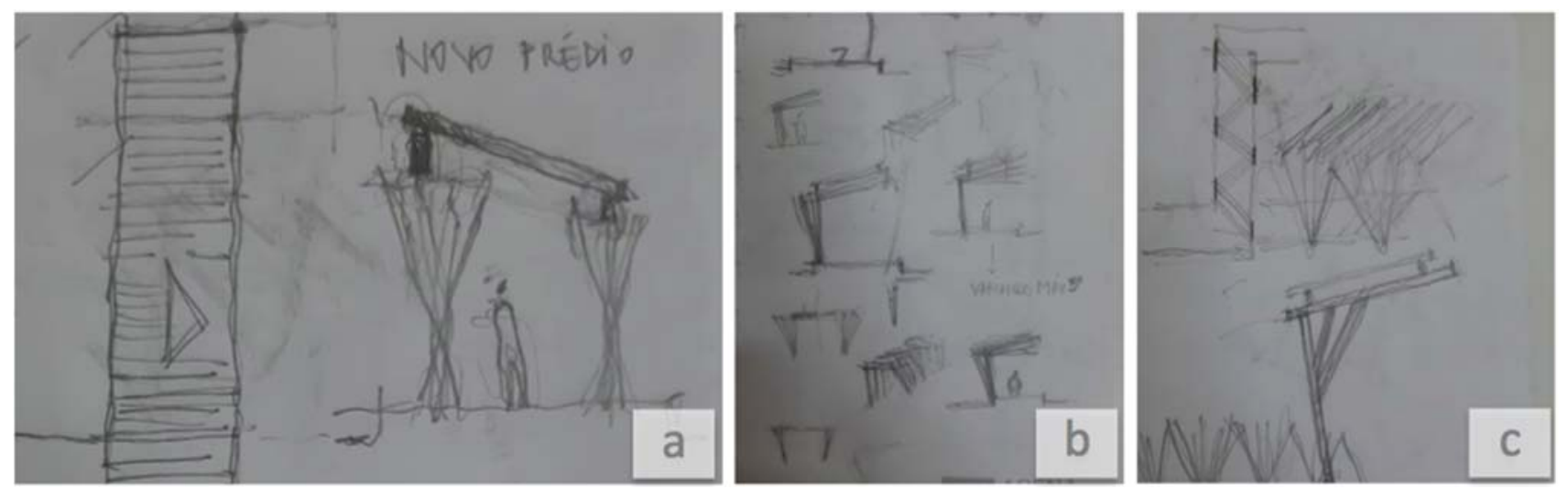

Fonte: Material produzido pelos autores, 2019.

O grupo partiu então para os softwares Rhinoceros e Grasshopper com as duas primeiras opções pensadas (Figura 4), a fim de melhor visualizar as possibilidades de parametrização e forma geral da estrutura.

Figura 4 - Início da modelagem no Rhinoceros e Grashopper
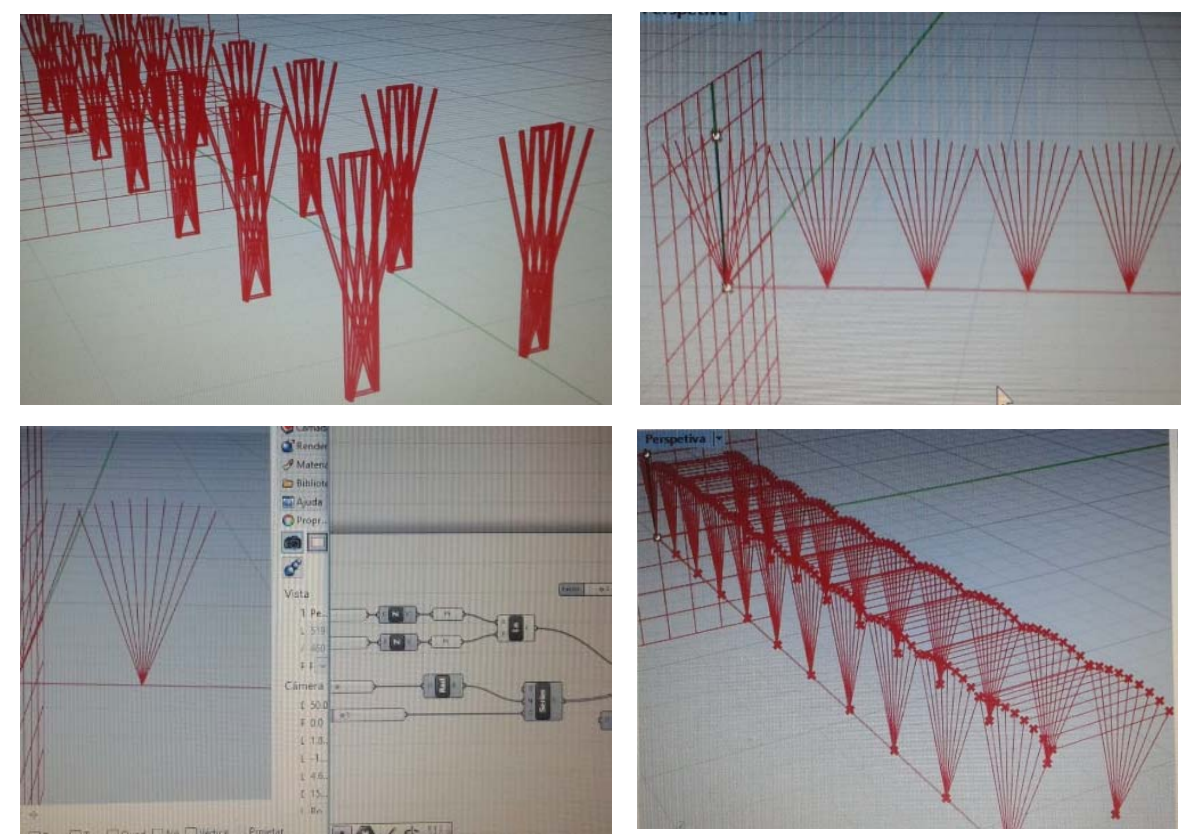
Nessas opções, a solução da cobertura não agradou, pois resultou em uma forma muito estática, sem muitas possibilidades de variação da estrutura.

Mantendo a ideia do leque em formato de "V", o grupo retomou aos estudos em croquis para o desenvolvimento de uma forma que possibilitasse mais dinamicidade. Assim, foi pensado em uma possibilidade de que o leque fosse se abrindo, mudando a altura e distanciamento entre as peças em uma progressão geométrica, causando um efeito de movimento às laterais (Figura 5).

Figura 5 - Croquis de evolução dos pilares no formato "V" em progressão geomátrica
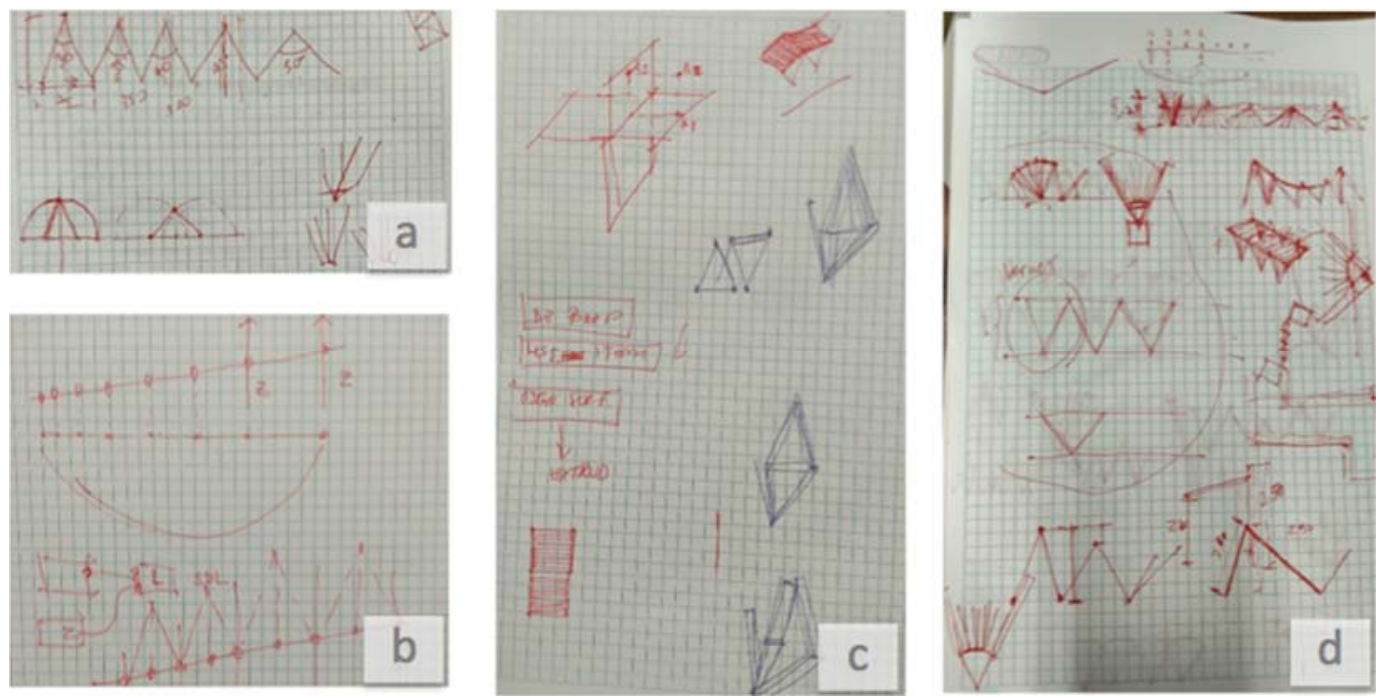

Fonte: Material produzido pelos autores, 2019.

Passou-se então à execução dessa última possibilidade no Rhinoceros (Figura 6). A princípio a ideia da progressão funcionou, mas houve dificuldade na implantação do modelo no arquivo final, pois a fórmula para se obter a progressão não se adequava à inclinação da rampa, fazendo com que o resultado não ficasse como pretendido.

Figura 6 - Desenvolvimento da opção em progressão geométrica no Rhinoceros e Grashopper

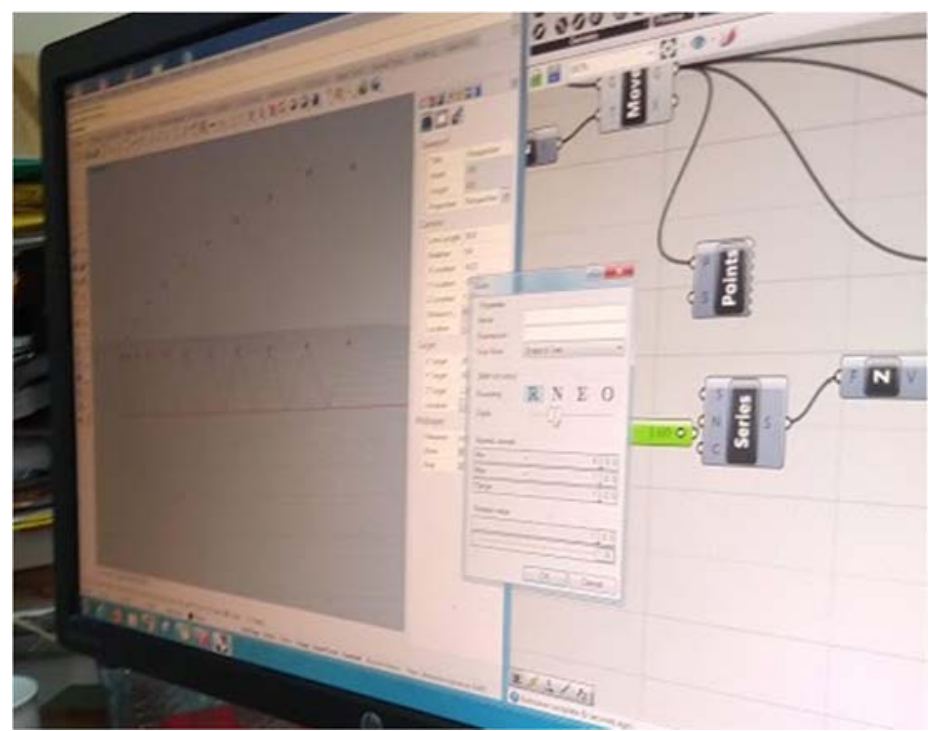


Sendo assim, o grupo retomou aos estudos em nível de croquis e recortes em papel, para definir uma nova possibilidade que atendesse às expectativas (Figura 7).

Foi descartada a variação da estrutura em progressão geométrica e foi retomada a forma do leque em "V" com mesmo espaçamento, mas com o uso da Polyline diretamente no Rhinoceros, foi possível criar um formato mais orgânico, que possibilitou variar alturas, distâncias, ângulos, coberturas, de acordo com a inclinação da rampa.

\section{Figura 7 - Retomada aos croquis e recortes para se pensar na estrutura}
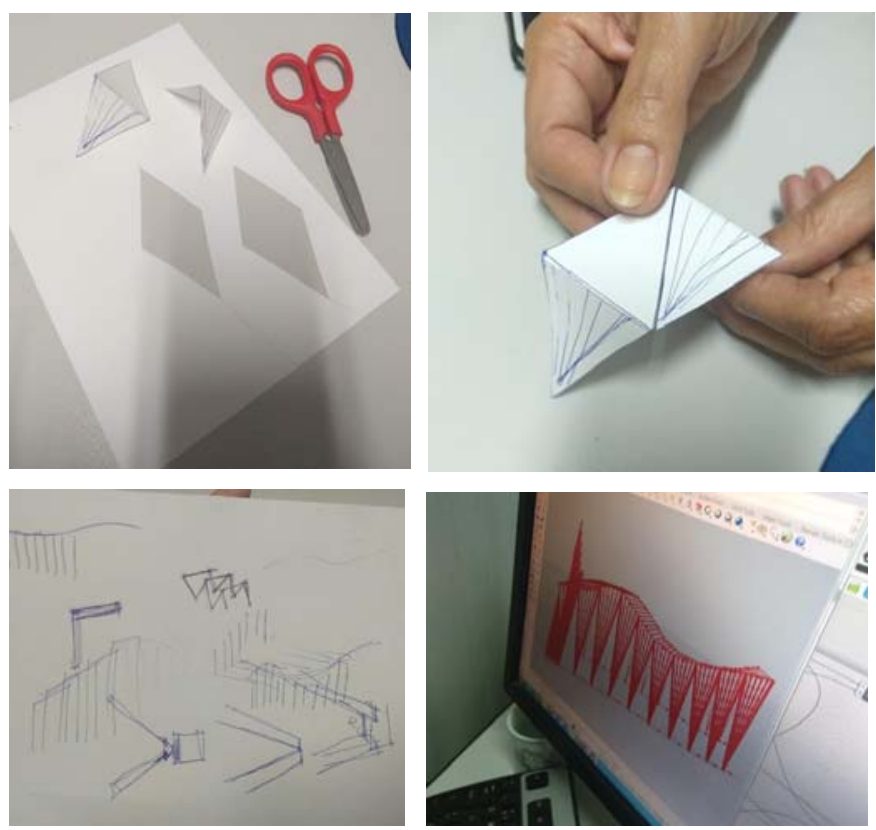

Fonte: Material produzido pelos autores, 2019.

Sendo aprovados os testes com essa última proposição, deu-se continuidade ao desenvolvimento nos softwares em uso, chegando a um modelo que permite variações nas quantidades de peças, tanto nos pilares quanto na cobertura, e possibilita diferentes inclinações e alturas (Figura 8).

Figura 8 - Tela de modelo final desenvolvido no Grasshoper

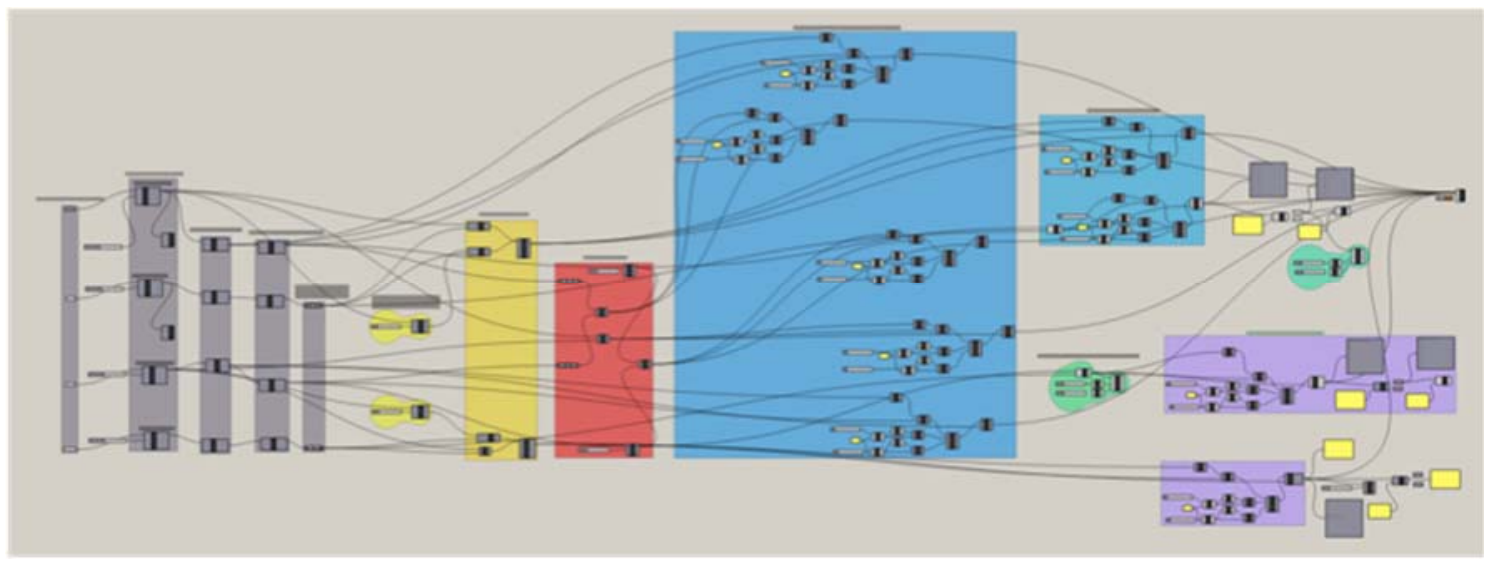

Fonte: Rhinoceros e Grasshoper, material produzido pelos autores, 2019. 
Cada retângulo demarcado na imagem acima indica um dos passos realizado no programa Grasshoper, necessários para obter-se a versão final da proposta. Como pode ser visto pela dimensão da fórmula gerada foi um longo processo que demandou muitos testes, até se chegar à solução desejada.

O desenvolvimento do algoritmo para a modelagem da passarela começou com a criação de quatro curvas no software Rhinoceros. Passamos então a trabalhar com o plug-in Grasshopper para gerar a parametrização da passarela. O primeiro passo foi introduzir quatro curvas na área de trabalho do Grasshopper com o comando Curve e com a opção set on curve "setamos" as curvas criadas no Rhinoceros. No segundo passo dividimos as curvas com o comando Divide Curve, neste momento criamos dez pontos superiores e dez pontos inferiores em cada par de curvas. No terceiro passo foram criadas Polylines.

Dando prosseguimento, no quarto passo com o comando Explode explodimos as polylines para gerar segmentos que definiram os pilares em $\mathrm{V}$. No quinto passo determinamos os pontos médios das curvas inferiores com o comando Point on Curve, para definir os pontos de apoio dos pilares em $\mathrm{V}$.

No sexto passo utilizamos o comando Shift List para ajustarmos os pontos que poderiam possibilitar a criação do pilar em $\mathrm{V}$, nas curvas superiores. Fato que permitiu a criação de duas linhas em cada par de curvas, utilizando os pontos da curva superior e os pontos médios da curva inferior, no sétimo passo. Neste momento os pilares em $\mathrm{V}$ ficaram concluídos.

No oitavo passo, para definirmos a cobertura, dividimos os segmentos explodidos nas curvas superiores e com o comando Line ligamos uns aos outros. Além disto, definimos os pontos médios desses segmentos e criamos novas linhas com os mesmos.

No nono passo para dar volume às linhas da cobertura, utilizamos os seguintes comandos: End Point; Plan Normal; Number Slider; Panel; Division; Neg; Construct Domain; Rectangle e Extrusion.

No décimo passo os mesmos comandos do passo anterior foram utilizados para a extrusão dos pilares. No décimo primeiro passo, eliminamos o pilar que ficou na frente da escada, para tanto utilizamos os comandos Split Tree, Panel e Brep. No décimo segundo passo, com os comandos Extend Curve e Neg determinamos a diminuição do tamanho dos caibros do pilar em $\mathrm{V}$ concluindo desta forma o algoritmo.

\section{Fixação da estrutura}

Durante o desenvolvimento do projeto, não houve tempo hábil para se chegar ao nível de detalhamento de fixação e junção dos elementos, mas o grupo pensou em alguns sistemas utilizando parafusos e chapas metálicas, exemplificadas na imagem abaixo (Figura 9).

Figura 9 - Formas de fixação da estrutura
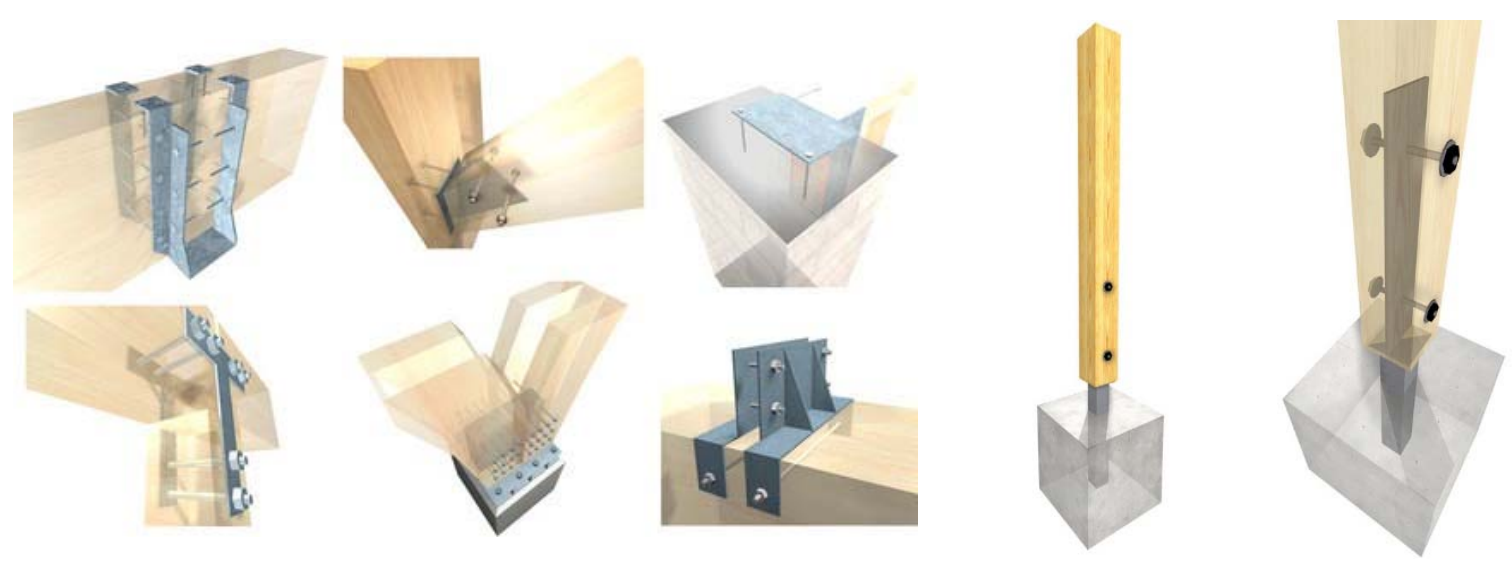

Fonte: Google imagens, alterado pelos autores, 2019. 
Para a fundação, o grupo considerou a possibilidade de execução de bases em concreto, nas quais seriam engastadas hastes de aço fixadas nas bases do pilares. A junção das peças do pilar, por sua vez, seria realizada através de chapas metálicas e parafusos. O mesmo sistema seria utilizado para a junção dos pilares e elementos da cobertura, fazendo assim o travamento da estrutura.

As peças em madeira teriam alturas e recortes variados, em função da posição dos elementos e do formato final escolhido, dentre as possibilidades fornecidas pela parametrização.

\section{Proposta final}

Finalizado o processo, o grupo chegou à proposta final (Figura 10) que atendeu tanto aos critérios de avaliação da disciplina, respeitando tanto as restrições e diretrizes gerais, quanto ao aspecto estético desejado.

Figura 10 - Perspectiva geral com implantação da estrutura final

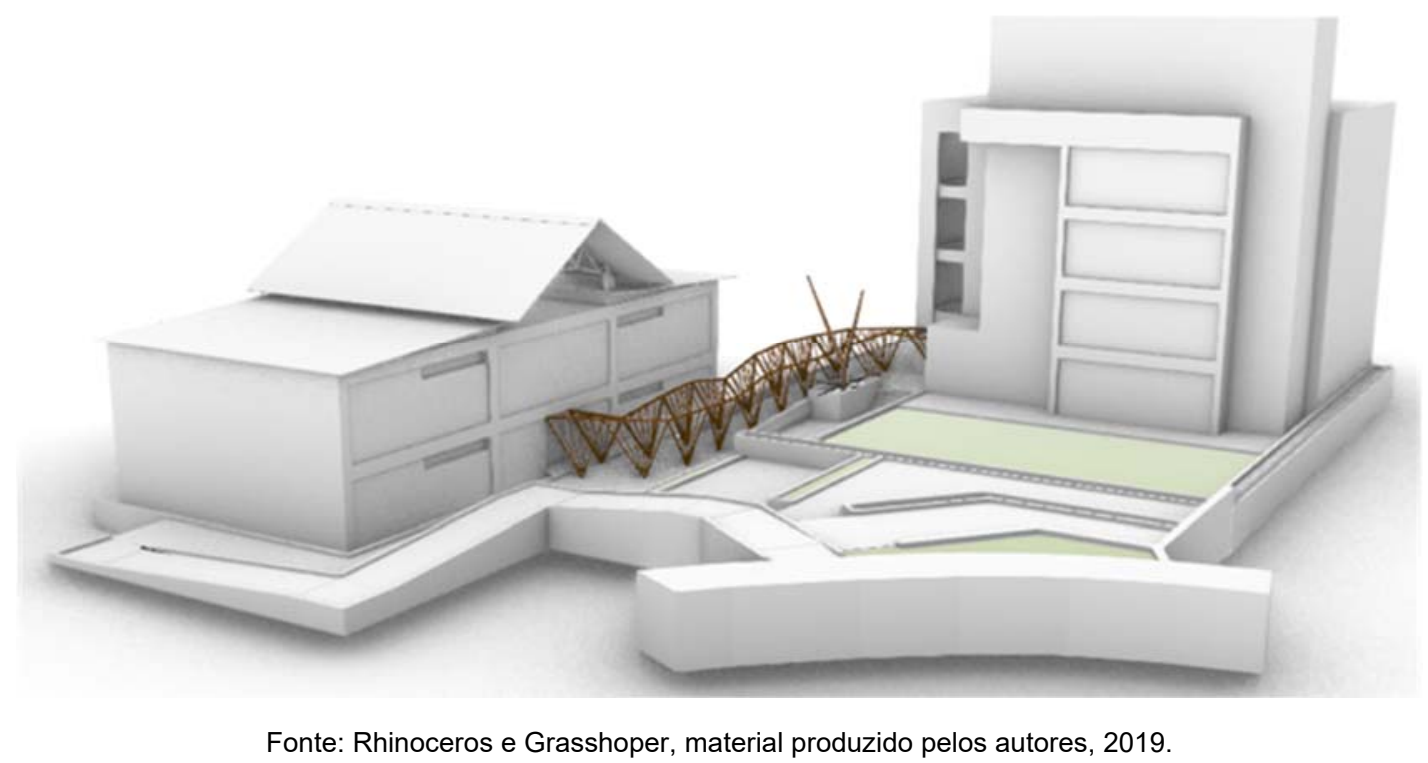

Como pode ser visto nas figuras abaixo (Figura 11 e Figura 12), o modelo permite variações nas quantidades de peças no pilar em "V" e na cobertura, de forma que se pode deixar a estrutura mais ou menos aberta.

Figura 11 - Variações nas quantidades de peças dos pilares

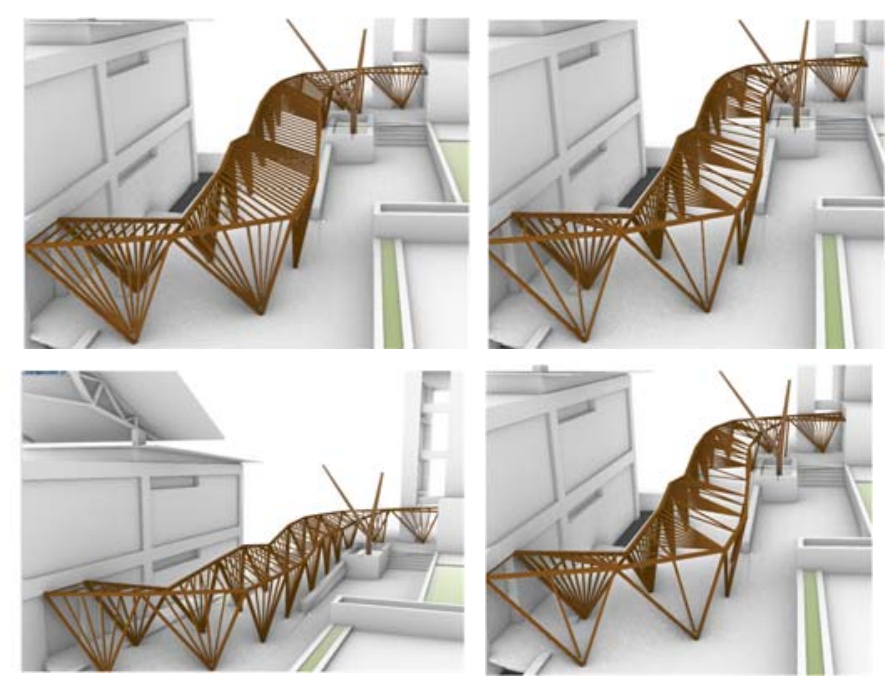

Fonte: Rhinoceros e Grasshoper, material produzido pelos autores, 2019. 
Figura 12 - Variações na quantidade de peças e formato da cobertura
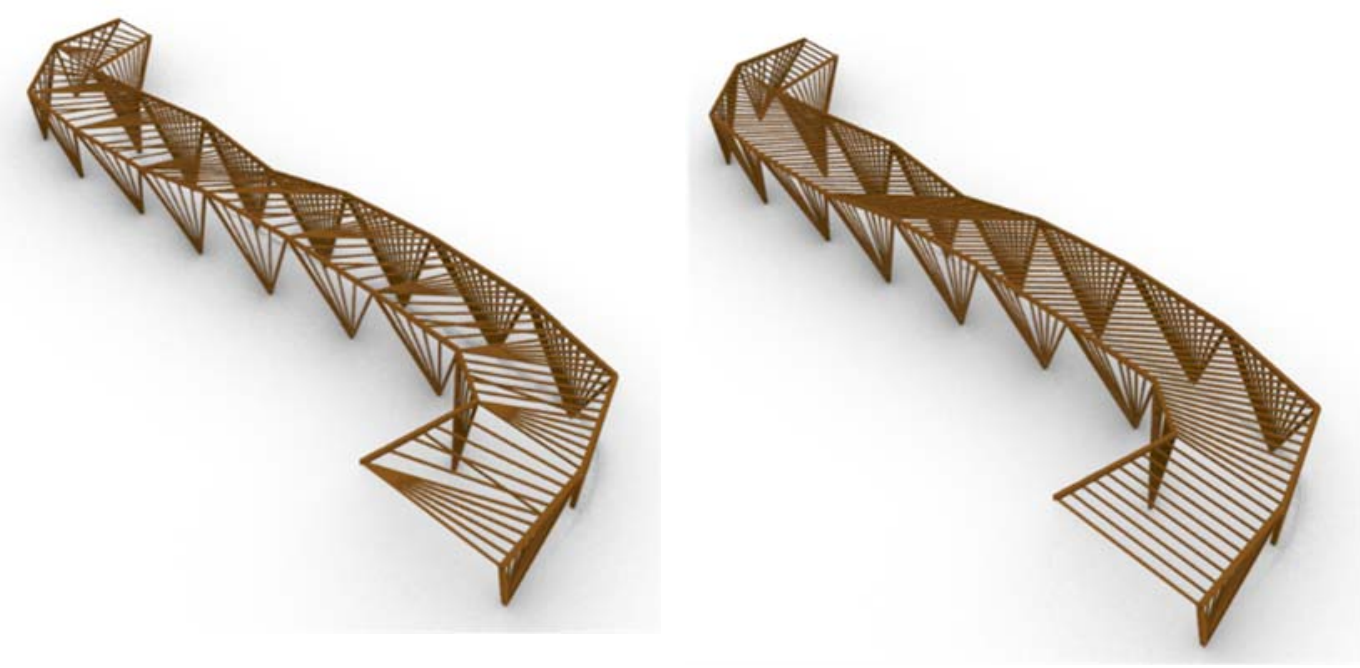

Fonte: Rhinoceros e Grasshoper, material produzido pelos autores, 2019.

A possibilidade em se mover os eixos horizontais e verticais dos pilares e cobertura também geram o efeito de dinamicidade desejado pelo grupo, como pode ser observado nas imagens a seguir (Figura 13).

Figura 13 - Visão interna e externa no ângulo do observador
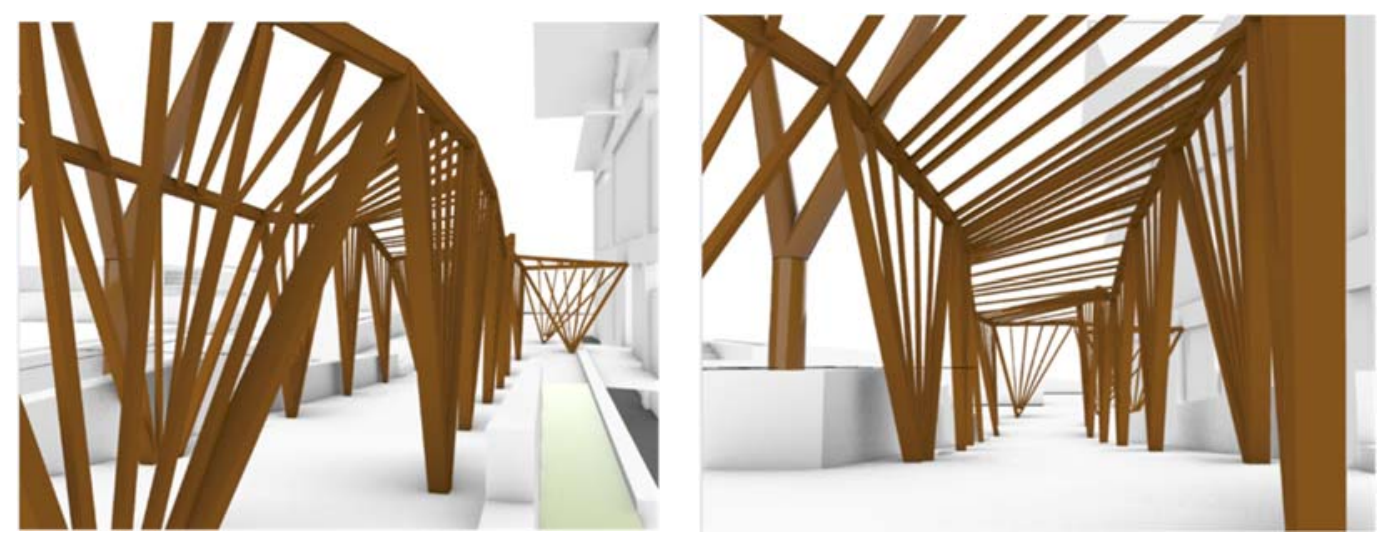

Fonte: Rhinoceros e Grasshoper, material produzido pelos autores, 2019.

\section{CONCLUSÃO}

O desenvolvimento de projetos de arquitetura a partir da modelagem paramétrica nos traz uma reflexão acerca das possibilidades criativas durante o processo de projeto, resultantes das combinações de parâmetros utilizados, neste caso, no software Grasshoper aplicado ao Rhinoceros. A oportunidade em produzir a proposta de um modelo computacional parametrizado foi um aprendizado enriquecedor, agregando conhecimento, e apresentando novos caminhos para o processo projetual. 
Importante destacar que com essa atividade ficou claro que o uso dessa ferramenta não elimina outras, na verdade ocorre exatamente o oposto, elas se complementam, sendo inclusive a concepção a nível de croquis fundamental para a evolução da proposta.

Além disto, o processo de projeto, feito de forma colaborativa entre os alunos e grupos, com o auxilio de professores, foi engrandecedor do ponto de vista da troca de informações e aprendizados, ampliados ao fim do curso.

Por fim, acredita-se que apesar de todas as dificuldades em virtude dos alunos não possuírem conhecimento aprofundado no uso dos softwares de desenho paramétrico, com o auxílio dos professores e muitas tentativas, erros e acertos, foi possível alcançar um resultado satisfatório.

\section{REFERÊNCIAS}

ARCHDAILY. Experiência de construção em madeira em Valparaíso: estruturas estáveis de curvatura dupla a partir da linha reta. Disponível em: <http://www.archdaily.com.br/br/801330/experiencia-de-construcao-em-madeira-emvalparaiso-estruturas-estaveis-de-curvatura-dupla-a-partir-da-linha-reta> Acesso em 27 de maio de 2019.

GAZETA DO POVO. Construída há 18 anos, passarela que liga dois campi da UFPR teve inspiração lúdica. Disponível em: <https://www.gazetadopovo.com.br/haus/arquitetura/a-historia-passarela-ufpr-corta-linha-verde/> Acesso em 27 de maio de 2019.

TEDESCHI, Arturo. AAD Algorithms-aided Design: Parametric Strategies Using Grasshopper. Edição Le Penseur, Roma, 2014.

\section{NOTAS}

\footnotetext{
${ }^{1}$ Disponível em: www.archdaily.com.br/br/801330/experiencia-de-construcao-em-madeira-em-valparaiso-estruturas-estaveis-decurvatura-dupla-a-partir-da-linha-reta, acesso em abril de 2019.

${ }^{2}$ Disponível em: www.archdaily.com.br/br/801330/experiencia-de-construcao-em-madeira-em-valparaiso-estruturas-estaveis-decurvatura-dupla-a-partir-da-linha-reta, acesso em abril de 2019.

${ }^{3}$ Disponível em: www.gazetadopovo.com.br/haus/arquitetura/a-historia-passarela-ufpr-corta-linha-verde/, acesso em abril de 2019.

${ }^{4}$ Disponível em: www.gazetadopovo.com.br/haus/arquitetura/a-historia-passarela-ufpr-corta-linha-verde/, acesso em abril de 2019.
}

NOTA DO EDITOR (*) O conteúdo do artigo e as imagens nele publicadas são de responsabilidade do(s) autor(es). 